\title{
Serum potassium responses to nebulized salbutamol administered during an acute asthmatic attack
}

\author{
D. DaCRUZ \& C. HOLBURN
}

Accident and Emergency Department, The Leicester Royal Infirmary, Leicester, England

\section{SUMMARY}

A prospective study of 20 patients presenting to an accident and emergency department with an exacerbation of pre-existing reversible airways disease was undertaken in order to determine whether such patients incurred any changes in their serum potassium following administration of $5 \mathrm{mg}$ of nebulized salbutamol.

Electrolytes were estimated before and $30 \mathrm{~min}$ after administration of nebulize salbutamol. No other drug was administered during this period.

Results indicate that nebulized salbutamol can cause a significant hypokalaemi response in such situations. Eight out of the 20 patients studied demonstrated falls in serum potassium of more than $0.3 \mathrm{mmol} / 1$. Most of the falls in serum potassium occurred in patients with low pre-treatment $\mathrm{PCO}_{2}$ values; a group of patients with less severe respiratory distress.

This preliminary study indicates that a further study aimed at elucidating the clinical significance of nebulized salbutamol-induced hypokalaemia is required.

\section{INTRODUCTION}

The administration of nebulized $\beta_{2}$-adrenoceptor agonists is an established treatment for acute asthmatic attacks. Previous authors have shown that intravenous $\beta_{2}$-adrenoceptor agonists are capable of producing a variety of biochemical responses, particularly hypokalaemia (Massara et al., 1976; Jenkins \& Marlin, 1981; Cheong et al., 1988). Similar responses have been reported in healthy, non-asthmatic volunteers administered nebulized salbutamol (Monie et al., 1980; Smith et al., 1984) but there has to date

Correspondence: Mr D. DaCruz, Senior Registrar, Accident and Emergency Department, The Leicester Royal Infirmary, Infirmary Square, Leicester LE1 5WW, England. 
been no prospective clinical study of serum potassium changes induced by nebulized salbutamol administered during the course of an acute asthmatic attack.

If hypokalaemia is induced during an acute asthmatic attack, it probably ought to be corrected (Cheong et al., 1988). A preliminary prospective study of 20 consecutive cases of acute asthma was undertaken in order to establish whether or not hypokalaemia occured in response to nebulized salbutamol.

\section{SUBJECTS AND METHODS}

All patients presented directly to the Accident and Emergency Department, Leicester Royal Infirmary, where they were initially assessed by a senior house officer. If this doctor made a diagnosis of reversible airways disease and decided that nebulized salbutamol would be the appropriate clinical therapy, the patient was entered to the study.

Before administration of any drugs (excluding oxygen), patients had their peak expiratory flow rate recorded and venous and arterial blood samples were obtained for urgent analysis. Urea and electrolytes were either measured on a SMAC 2 or 508 multichannel analyser giving an intersample error of less than $1 \%$. This reproducibility was confirmed by sampling normal subjects in tandem with the patients in the study. Arterial blood sample analysis was performed on an Instrumentation Lab System 1302 machine.

After blood letting, each patient received $5 \mathrm{mg}$ of nebulized salbutamol diluted to a total volume of $5 \mathrm{ml}$ in normal saline administered via a close-fitting Hudson mask driven by oxygen with a delivery time of $10 \mathrm{~min}$. No other drugs were administered during the ensuing $30 \mathrm{~min}$, after which peak expiratory flow rate and venous sampling for potassium and glucose were repeated. The timing of the repeat estimations ( $30 \mathrm{~min}$ ) was based on the experience of Smith et al. (1984).

\section{RESULTS}

Twenty patients (12 male, 8 female) with a mean age of 39 years were studied. One of these patients was eliminated because pre-treatment blood samples were haemolysed. All patients improved subjectively following nebulized salbutamol and showed objective improvement with an increase in the peak expiratory flow rate. The average improvement was $60 \%$ over pre-treatment level (range 10-256\%).

Arterial blood analysis showed that five patients had respiratory alkalosis $(\mathrm{pH} \geqslant 7 \cdot 45$, $\left.\mathrm{PCO}_{2} \leqslant 4 \cdot 7\right)$ and 5 had an uncompensated respiratory acidosis $\left(\mathrm{pH} \leqslant 7 \cdot 35, \mathrm{PCO}_{2} \geqslant 5 \cdot 5\right)$.

Prior to treatment, all 19 patients studied had normal serum potassium levels. Thirty minutes after receiving nebulized salbutamol the following changes in potassium were observed.

(1) Eight patients $(42 \%$ ) sustained falls in serum potassium of $>0.3 \mathrm{mmol}$ (Table 1 ). In this group the largest fall was $1.0 \mathrm{mmol}$ with a mean fall of $0.54 \mathrm{mmol}$. Five of these patients had a corresponding rise in their serum glucose level. 
Table 1 Patients with a hypokalaemic response of $\geqslant 0.3 \mathrm{mmol} / 1$

\begin{tabular}{|c|c|c|c|c|c|c|c|c|}
\hline & \multicolumn{8}{|c|}{ Patient no. } \\
\hline & 2 & 3 & 6 & 8 & 9 & 12 & 18 & 20 \\
\hline Potassium (pre-treatment)** & $3 \cdot 2$ & $4 \cdot 2$ & 4.5 & 4.9 & $4 \cdot 5$ & $4 \cdot 2$ & $4 \cdot 2$ & 4.5 \\
\hline Potassium (post-treatment)** & $2 \cdot 7$ & 3.6 & $4 \cdot 2$ & $4 \cdot 2$ & $4 \cdot 1$ & $3 \cdot 2$ & 3.9 & $4 \cdot 0$ \\
\hline PEFR (pre-treatment)* & 100 & 250 & 150 & 250 & 370 & 275 & 125 & 110 \\
\hline PEFR (post-treatment)* & 125 & 350 & 320 & 420 & 550 & 350 & 220 & 140 \\
\hline Glucose (pre-treatment) ${ }^{* *}$ & $6 \cdot 0$ & $5 \cdot 7$ & $6 \cdot 1$ & $4 \cdot 6$ & $4 \cdot 8$ & $6 \cdot 5$ & $5 \cdot 1$ & $7 \cdot 8$ \\
\hline Glucose (post-treatment) ${ }^{* *}$ & $5 \cdot 3$ & $6 \cdot 2$ & $6 \cdot 8$ & 4.9 & $5 \cdot 1$ & $7 \cdot 9$ & 4.9 & $6 \cdot 8$ \\
\hline \multicolumn{9}{|l|}{ Blood Gases (pre-treatment) } \\
\hline $\mathrm{PCO}_{2}(\mathrm{kPa})$ & $3 \cdot 3$ & 3.5 & $3 \cdot 6$ & $3 \cdot 8$ & $4 \cdot 2$ & $3 \cdot 8$ & $3 \cdot 6$ & $6 \cdot 50$ \\
\hline $\mathrm{pH}$ & $7 \cdot 49$ & $7 \cdot 40$ & $7 \cdot 56$ & $7 \cdot 42$ & $7 \cdot 45$ & $7 \cdot 41$ & $7 \cdot 52$ & $7 \cdot 32$ \\
\hline
\end{tabular}

* Peak expiratory flow rate ( $1 / \mathrm{min})$.

** $\mathrm{mmol} / \mathrm{l}$.

(2) In nine patients the serum potassium altered by $<0.3 \mathrm{mmol} / 1$. These alterations could be explained by the normal $1 \%$ error margin allowed by the equipment used.

(3) Two patients had increases in their serum potassium, one of $0.3 \mathrm{mmol}$ and one of $1.3 \mathrm{mmol}$ (Table 2).

\section{DISCUSSION}

There is considerable controversy concerning serum potassium responses to therapeutic doses of nebulized salbutamol. There has been no prospective study of this response in patients actually suffering an acute exacerbation of asthma, though there have

Table 2 Patients not exhibiting a substantial hypokalaemic response

Patient no.

\begin{tabular}{|c|c|c|c|c|c|c|c|c|c|c|c|}
\hline & \\
\hline & 1 & 4 & 5 & 7 & 11 & 13 & 14 & 15 & 16 & 17 & 19 \\
\hline Potassium (pre-treatment) ${ }^{* *}$ & $4 \cdot 1$ & $3 \cdot 7$ & $3 \cdot 8$ & 3.9 & $4 \cdot 0$ & $4 \cdot 3$ & $4 \cdot 6$ & $4 \cdot 1$ & $4 \cdot 8$ & $4 \cdot 1$ & $4 \cdot 6$ \\
\hline Potassium (post-treatment) ${ }^{* *}$ & 3.9 & $3 \cdot 8$ & 3.9 & $4 \cdot 1$ & $5 \cdot 3$ & $4 \cdot 2$ & 4.9 & $4 \cdot 1$ & $4 \cdot 7$ & 3.9 & $4 \cdot 5$ \\
\hline PEFR (pre-treatment)* & 70 & 90 & 170 & 50 & 90 & 90 & 90 & 100 & 125 & 220 & 150 \\
\hline PEFR (post-treatment)* & 130 & 150 & 260 & 150 & 110 & 150 & 100 & 170 & 320 & 260 & 180 \\
\hline Glucose (pre-treatment) ${ }^{* *}$ & $23 \cdot 6$ & $6 \cdot 1$ & 4.9 & $4 \cdot 7$ & $5 \cdot 4$ & $4 \cdot 3$ & $11 \cdot 3$ & $5 \cdot 4$ & $5 \cdot 4$ & $5 \cdot 8$ & $6 \cdot 3$ \\
\hline Glucose (post-treatment)** & NA & $7 \cdot 0$ & $5 \cdot 0$ & $5 \cdot 3$ & 6.6 & $4 \cdot 5$ & $11 \cdot 7$ & $6 \cdot 6$ & $5 \cdot 6$ & $6 \cdot 0$ & $8 \cdot 8$ \\
\hline $\mathrm{PCO}_{2}(\mathrm{kPa})$ & $5 \cdot 8$ & $4 \cdot 2$ & $5 \cdot 21$ & $5 \cdot 0$ & $7 \cdot 2$ & $5 \cdot 05$ & $6 \cdot 76$ & $3 \cdot 7$ & $4 \cdot 7$ & $5 \cdot 7$ & $4 \cdot 7$ \\
\hline $\mathrm{pH}$ & $7 \cdot 23$ & $7 \cdot 45$ & $7 \cdot 40$ & $7 \cdot 38$ & $7 \cdot 2$ & $7 \cdot 32$ & $7 \cdot 22$ & $7 \cdot 40$ & $7 \cdot 51$ & $7 \cdot 34$ & $7 \cdot 38$ \\
\hline
\end{tabular}

* Peak expiratory flow rate $(1 / \mathrm{min})$.

** mmol/1 
recently been a number of people expressing differing opinions on the subject in stable asthmatics and in patients who have received a number of anti-asthma drugs (Ebden et al., 1987; Sears, 1987). What is not in doubt is that were hypokalaemia to be induced by therapeutic dose of nebulized salbutamol in an already stressed patient it could lead to serious cardiovascular side-effects. Indeed, a recent report on asthmatics from New Zealand (Godden \& Symon, 1987) has implied that hypokalaemia may have been the cause of some of their deaths whilst on nebulizer treatment.

As no other drug was administered between blood sample estimations during the course of this study, it appears reasonable to link the administration of nebulized salbutamol to the resulting hypokalaemia. Most of the large falls in serum potassium occurred in patients with low pre-treatment $\mathrm{PCO}_{2}$ values-patients with less severe respiratory disease. A possible explanation for this phenomenon is that an already maximally stressed patient may be incapable of responding metabolically to the adrenalin-mediated side-effects of salbutamol.

Whilst we cannot correlate the changes in serum potassium to any specific factors in the history or drug therapy, this study shows that it is possible to induce substantial changes in serum potassium in submaximally stressed patients using nebulized salbutamol.

A larger study must be undertaken if the clinical significance of such changes is to be substantiated and risk groups identified. It is possible that patients who are hypoxic, those already on diuretics and/or steroids, and those who require additional bronchodilator therapy with intravenous aminophylline may be at risk.

\section{ACKNOWLEDGEMENTS}

We are grateful to Mr M. Reichl, Senior Registrar in Accident and Emergency, for his help with this project before his departure to Southampton.

We are also grateful to Roberta Sutton for her help with preparing the manuscript.

\section{REFERENCES}

Cheong B., Reynolds S. R., Rajan G. \& Ward M. J. (1988) Intravenous beta agonist in severe acute asthma British Medical fournal 297, 448-50.

Ebden P., Farrow R. P., Shaw D. \& Cookson J. B. (1987) Seventy-five deaths in asthmatics prescribed home nebulizers (letter) British Medical fournal 294, 972.

Godden D. J. \& Symon D. N. K. (1987) Seventy-five deaths in asthmatics prescribed home nebulizers (points) British Medical fournal 294, 1356.

Jenkins C. R. \& Marlin G. E. (1981) The metabolic actions of intravenous salbutamol and aminophylline singly and in combination. British fournal of Clinical Pharmacology 11, 197-201.

Massara F., Fassio V., Camanni F. et al. (1976) Some metabolic and hormonal effects of salbutamol in man. Acta Diabetologica Latina 13, 146-53.

Monie R. D. H., Hartley J. P. R. \& Winston M. D. (1980) Metabolic reponses to inhaled salbutamol. British fournal of Diseases of the Chest 74. 

Sears M. R. (1987) Seventy-five deaths in asthmatics prescribed home nebulizers. British Medical fourna $\frac{\overline{3}}{0}$
294.

Smith S. R., Ryder C., Kendall M. J. \& Holder R. (1984) Cardiovascular and biochemical responses tᄌ nebulized salbutamol. British fournal of Clinical Pharmacology 18, 641-4. 